\title{
Maria do Carmo Campello de Souza (1936-2006)*
}

\author{
Eduardo Kugelmas
}

$\mathrm{E}$ m fevereiro último, o falecimento de Maria do Carmo Campello de Souza, Carmute como era por todos conhecida, empobreceu as comunidades a que pertencia de forma quase irreproduzível em palavras. Não apenas sua obra, mas sua presença, sua verve, seu humor mordaz, sua capacidade de desconcertar e encantar os mais variados interlocutores a farão sempre lembrada por todos que a conheceram.

Logo após terminar o curso de ciências sociais na antiga Faculdade de Filosofia, Ciências e Letras da Universidade de São Paulo - USP, o saudoso casarão gris da Rua Maria Antônia, no bairro paulistano de Vila Buarque, iniciou sua carreira acadêmica no campo da ciência política como integrante do grupo de pesquisa coordenado por Paula Beiguelman. Seu primeiro trabalho importante, o artigo "O Processo Político-Partidário na Primeira República" foi publicado em 1967 no livro organizado por Carlos Guilherme Mota, Brasil em Perspectiva, e é até hoje uma referência importante nos estudos sobre o período histórico que se estende da queda do Império à Revolução de 1930. Iniciou também nesta época suas atividades docentes, despertando o interesse de

\footnotetext{
* Este texto se baseia na intervenção do autor feita na mesa-redonda em homenagem à Maria do Carmo Campello de Souza, com a participação também de Célia Galvão Quirino, Cícero Araújo, Fernando Limongi e Francisco Weffort, realizada na Faculdade de Filosofia, Letras e Ciências Humanas - FFLCH, da Universidade de São Paulo - USP, em 14 de março de 2006.
}

DADOS - Revista de Ciências Sociais, Rio de Janeiro, Vol. 49, nํ1, 2006, pp. 5 a 10. 
muitos jovens promissores pelo estudo das instituições políticas brasileiras.

Não foi poupada pelo turbilhão do período repressivo aberto pelo Ato Institucional $\mathrm{n}^{-}$5, e enfrentou com estoicismo um período de prisão. Ao regressar às atividades acadêmicas, dedicou-se ao trabalho de pesquisa que culminou em sua tese de doutorado, intitulada Estado e Partidos Políticos no Brasil-1930 a 1964, a qual teve como orientador Francisco Weffort, e foi publicada como livro em 1976. "Temos um grande livro" afirmou com ênfase Vítor Nunes Leal ao prefaciar a obra.

Passadas três décadas, o impacto seminal desse livro pode ser mensurado pelas reedições, por sua presença indispensável nas bibliografias dos cursos sobre as instituições políticas brasileiras e pelos muitos trabalhos que não só influenciou como inspirou.

Três principais eixos de reflexão nortearam seu trabalho de pesquisa. Tomando o sistema partidário como unidade de análise, Carmute demonstrou cabalmente a fecundidade desta abordagem para a compreensão da estrutura e dinâmica do sistema político do período 1946-64, necessária também para a avaliação mais exata do papel de cada um dos partidos.

Ressaltando a função governativa e o papel dos partidos no policy-making e no conteúdo das decisões, abriu caminho para uma melhor compreensão da importância dessa dimensão antes pouco estudada. Nesta trilha, graças ao uso imaginoso do clássico artigo de Theodore Lowi sobre as arenas políticas (a distributiva, a redistributiva e a regulatória), sugeriu pistas fecundas para iluminar o estudo da relação entre sistema partidário e ação estatal. Com isto, antecipou e influenciou a constituição de uma importante área de pesquisa, a da análise das políticas públicas.

Mas talvez tenha sido o terceiro dos seus eixos analíticos o mais original e decisivo para fazer desse livro um clássico. Ao sublinhar a importância dos condicionantes estatais para o estudo dos sistemas partidários, Carmute reconstruiu a história das origens da estrutura política do período 1946-64, dando ênfase à continuidade até então subestimada entre este e o Estado Novo. Recordando a centralização burocrática e militar, o surgimento dos novos papéis econômicos do poder central e a consolidação de uma "ideologia de Estado", na expressão de Bolívar Lamounier, sua análise demonstrou cabalmente como a emergên- 
cia do sistema partidário em torno do Partido Social Democrata-PSD, da União Democrática Nacional -UDN e do Partido Trabalhista Brasileiro - PTB teve suas raízes no período anterior.

Sem subestimar a importância do novo quadro institucional e da Constituição de 1946, essa abordagem representou um marco de referência indispensável para a compreensão do experimento democrático e do extenso período histórico que é chamado, não por acaso, a "Era Vargas".

Para os mais jovens, que já tiveram seu contato com essa problemática, em um contexto político e intelectual tão transformado, não é fácil avaliar o quanto havia de inovação no trabalho de Carmute. Tomar como tema o estudo do sistema partidário em um momento de extremado autoritarismo, quando mal se entreviam os primeiros laivos da abertura, era já surpreendente. Recusar o economicismo tosco e o esquematismo pseudomarxista tão freqüentes nas análises políticas então em voga exigia uma certa dose de ousadia.

Desenvolver um trabalho entre a história e a ciência política, de natureza verdadeiramente interdisciplinar, quando o contato entre as disciplinas das ciências humanas era muitas vezes pregado mas poucas vezes praticado também significou uma abertura de caminhos.

Os estudos feitos posteriormente sobre os partidos, como o da UDN por Maria Victória Benevides, o do PSD por Lucia Hippolito e do PTB por Lucila Neves Salgado demonstram a importância da abordagem inaugurada por Carmute. Também os estudos sobre o Estado desenvolvimentista, como o de Sônia Draibe, foram marcados por sua influência.

A repercussão do livro tornou Carmute uma presença requestada nos debates e discussões sobre os rumos do país, no momento em que a intelectualidade participava ativamente da luta pela redemocratização. Assim, além das tarefas de docente e pesquisadora do Departamento de Ciência Política da USP, passou a colaborar na imprensa. Em 1981, foi uma das fundadoras do Instituto de Estudos Econômicos, Sociais e Políticos de São Paulo - IDESP, juntamente com outros cientistas sociais como Bolívar Lamounier, Maria Teresa Sadek e Sérgio Miceli. Nesta entidade, organizou seminários e coordenou grupos de pesquisa sobre temas político-institucionais e, mais recentemente, sobre migrações. 
Depois de sua aposentadoria na USP, iniciou uma frutífera colaboração com o Institute of Latin American and Iberian Studies - ILAIS, da Columbia University, onde foi professora-visitante por vários anos. Sua presença como docente, orientadora e pesquisadora deixou marcas fortes nesta instituição*, em um momento de fervilhamento intelectual e de intensa curiosidade sobre a trajetória das transições democráticas vividas pelo Brasil e por outros países latino-americanos. O livro organizado por Alfred Stepan, Democratizing Brazil (1989) reflete estas interrogações e inquietudes sobre os rumos do país na complexa e multifacetada conjuntura do período José Sarney. O conhecido texto de Carmute, "A Nova República sob a Espada de Damocles" encerra o volume. Sua análise, como o título indica, é marcada por forte cautela. Sublinhando as particularidades do processo de transição e a fragilidade da aliança Partido do Movimento Democrático Brasileiro - PMDBPartido da Frente Liberal -PFL, vê a transição como incompleta, e a situação econômica marcada pela crise da dívida externa e pela ameaça de hiperinflação como esfinge ameaçadora. Cunhando uma expressão que viria a ser muito citada e utilizada nos estudos sobre a transição, "centrismo invertebrado", avaliou com ceticismo a performance da antiga oposição ao regime militar como formuladora de políticas alternativas. Traçando um feliz paralelo entre algumas características do processo em curso e a redemocratização de 1946 já por ela estudada, interrogou-se sobre as potencialidades de consolidação bem-sucedida do novo sistema partidário.

Um tema pouco lembrado das transições latino-americanas, o novo papel da direita, atraiu sua curiosidade e de outros pesquisadores. Com Douglas Chalmers e Atílio Borón, Carmute organizou em 1990 um seminário no ILAIS que teve como resultado final o livro editado pelos três: The Right and Democracy in Latin America (1992). No seu capítulo sobre o Brasil, ela discute a peculiar conjuntura da eleição de Fernando Collor e dos começos de seu governo. Enfatiza a ascensão no país de uma corrente de pensamento econômico liberal e os desafios trazidos pela crise do paradigma varguista, que marcara por décadas a economia política brasileira.

Retornando a um tema que sempre a interessara, elaborou um texto infelizmente não publicado sobre "Aspectos Político-Institucionais do

\footnotetext{
* No dia 2 de março do corrente ano, o ILAIS organizou um seminário de homenagem póstuma a Carmute, com a participação, entre outros, de Alfred Stepan, Douglas Chalmers, Paulo Sérgio Pinheiro e Ralph Della Cava.
} 
Federalismo", parte de um projeto de pesquisa realizado em 1993 pela Fundação do Desenvolvimento Administrativo de São Paulo - Fundap. Neste trabalho, Carmute retoma temas tratados no seu livro já então clássico, desta vez enfatizando mais a complexidade de um sistema político em que a centralização burocrática coexistia com a cooptação de elites regionais. Aponta também para as potencialidades de uma abordagem mais próxima da sociologia política para o estudo dos processos de centralização/descentralização do poder, ao utilizar a contribuição de autores como Michael Mann e Joel Migdal.

Nos anos mais recentes, o foco dos interesses de Carmute passou a ser o trabalho comunitário, como colaboradora do programa Comunidade Solidária, dirigido por Ruth Cardoso, e como participante do conjunto de projetos de Ivaldo Bertazzo, que combinam criação artística e objetivos socioeducacionais. Na colaboração com Bertazzo, escreveu textos e roteiros para os espetáculos Carnaval dos Animais, Além da Linha d'Água e Mãe Gentil.

Manteve, ao mesmo tempo, seus laços com o mundo acadêmico como coordenadora de projetos do IDESP sobre migrações. Continuou a acompanhar o caleidoscópico processo político do país, embora não aceitasse mais convites para seminários, mesas-redondas e entrevistas à imprensa. Alguns interlocutores mais constantes, como Amaury de Souza, Célia Galvão Quirino, José Artur Giannotti, Roberto Schwarz e o autor destas linhas podem testemunhar a argúcia de suas observações.

Nos últimos meses de vida, já gravemente enferma, dedicou-se com o denodo que lhe era peculiar ao espetáculo da parceria Dança Comunidade entre o Serviço Social do Comércio - SESC-SP e Ivaldo Bertazzo, Milágrimas. Como parte deste projeto, organizou o volume Tenso Equilíbrio na Dança da Sociedade (2005), com a participação de cientistas sociais, administradores e romancistas, no qual se investiga a relação entre a cultura e o trânsito social entre o centro e a periferia da metrópole, as imensas dificuldades e as muitas possibilidades do trabalho de integração social de adolescentes e jovens ameaçados pela marginalização.

No seu texto para esse livro, "Periferia, Cultura e Trânsito Social", a mesma discute as potencialidades deste trabalho, sem utopismos mas sem desânimo. O ponto central deste livro, como também do projeto específico em que está inserido e do conjunto de esforços de que faz parte, escreve Carmute, "[...] relaciona-se à importância da igualdade de direitos à cultura a todos no sentido de ampliar o leque de oportunidades para os habitantes da assim chamada 'periferia', em seu percur- 
Eduardo Kugelmas

so difícil de integração social e de incorporação do sentimento de pertencer à sociedade".

Que seja este seu testamento. 